\title{
Internal jugular vein blood flow in the upright position during external compression and increased central venous pressure: an ultrasound study in healthy volunteers

\author{
Débit sanguin de la veine jugulaire interne en position debout \\ pendant une compression externe et augmentation de la pression \\ centrale veineuse : une étude échographique auprès de volontaires \\ sains
}

\author{
Tze Yeng Yeoh, MBChB, MMed (Anaes) - Lashmi Venkatraghavan, MD, FRCA, FRCPC • \\ Joseph A. Fisher, MD • Massimiliano Meineri, MD
}

Received: 25 October 2016/Revised: 6 April 2017/Accepted: 15 May 2017/Published online: 2 June 2017

(c) Canadian Anesthesiologists' Society 2017

\begin{abstract}
Background External compression of the jugular veins is an effective method to increase intracranial blood volume and brain stiffness in rats and healthy volunteers. It has been reported that, on assuming an upright posture, cerebral venous drainage is distributed away from the internal jugular veins (IJVs) to the cervical venous plexus, causing complete collapse of the IJV. If so, it is not clear why external IJV compression would increase intracranial blood volume, but the latter is frequently observed in neurosurgery in the sitting position. The aim of this study was to observe the effect of external IJV compression and the Valsalva maneuver on the change in IJV crosssectional area and IJV flow in volunteers in the upright posture.

Methods After Research Ethics Board approval, we used ultrasound to evaluate both IJV cross-sectional areas and peak velocities in ten healthy volunteers in the sitting position. With the volunteers breathing normally at rest, we applied the Valsalva maneuver along with circumferential supraclavicular compression of $15 \mathrm{mmHg}$. Imaging was
\end{abstract}

T. Y. Yeoh, MBChB, MMed (Anaes) · L. Venkatraghavan, MD, FRCA, FRCPC · J. A. Fisher, MD · M. Meineri, MD Department of Anesthesia and Pain Management, University Health Network, University of Toronto, Toronto, ON, Canada

M. Meineri, MD (ه)

Department of Anesthesia, Toronto General Hospital, University

Health Network, University of Toronto, 200 Elizabeth Street

EN3-400, Toronto, ON M5G 2C4, Canada

e-mail: massimiliano.meineri@uhn.ca performed at the level of the cricoid cartilage and at the most superior level under the mandible. The IJV flow was calculated using the product of Doppler velocity and IJV cross-sectional area.

Results Flow was detected in both IJVs of all subjects. The median [interquartile range] cross-sectional area for the right IJV at the level of the cricoid was 0.04 [0.03-0.08] $\mathrm{cm}^{2}$ (baseline), with collar $0.4[0.2-0.6] \mathrm{cm}^{2}(P=0.003$ compared with baseline). There were no significant changes in the median blood flow.

Conclusions Compression of the internal jugular veins or an increase in intrathoracic pressure does not reduce venous drainage but actually may increase intracranial venous volume.

\section{Résumé}

Contexte La compression externe des veines jugulaires est une méthode efficace pour augmenter le volume sanguin intracrânien et la rigidité cérébrale chez les rats et les volontaires sains. Il a été rapporté que, en adoptant une position debout, le drainage veineux cérébral est redirigé des veines jugulaires internes (VJI) vers le plexus veineux cervical, ce qui provoque un collapsus complet de la VJI. Si tel est le cas, nous ne savons pas pourquoi la compression externe de la VJI augmenterait le volume sanguin intracrânien, mais on observe souvent ce phénomène lors des cas de neurochirurgie en position assise. L'objectif de cette étude était d'observer l'effet d'une compression externe de la VJI et de la manouvre de Valsalva sur le changement d'aire de la section transverse 
de la VJI et le flot de la VJI chez des volontaires en position debout.

Méthode Après avoir reçu le consentement du Comité d'éthique de la recherche, nous avons utilisé l'échographie pour évaluer les aires de la section transverse et les vélocités maximales de la VJI auprès de dix volontaires sains en position assise. Alors que les volontaires respiraient normalement au repos, nous avons appliqué une manouvre de Valsalva ainsi qu'une compression supraclaviculaire périphérique de $15 \mathrm{mmHg}$. Nous avons obtenu des images au niveau du cartilage cricoïde et au niveau le plus élevé sous la mâchoire inférieure. Le flot de la VJI a été calculé en utilisant le produit de la vélocité Doppler et de l'aire de la surface transverse de la VJI.

Résultats Un flot a été détecté dans les deux VJI chez tous les volontaires. L'aire de la surface transverse médiane [écart interquartile] pour la VJI droite au niveau de la cricoïde était de 0,04 [0,03-0,08] $\mathrm{cm}^{2}$ (valeur de base), avec un collet à $0,4 \quad[0,2-0,6] \quad \mathrm{cm}^{2} \quad(P=0,003$ comparativement à la valeur de base). Aucun changement significatif n'a été observé en ce qui a trait au flot sanguin médian.

Conclusion $\mathrm{Ni}$ la compression des veines jugulaires internes, ni l'augmentation de la pression intrathoracique ne réduit le drainage veineux, mais ces manœuvres pourraient en fait augmenter le volume veineux intracrânien.

Intracranial compliance is important in day-to-day life to accommodate acute changes in cerebral blood volume from each cardiac cycle, changes in venous outflow resistance, ${ }^{1}$ and chronic changes in intracranial blood volume from periodic hypercapnia (such as during sleep apnea). The cerebrospinal fluid (CSF) is initially displaced into the compliance of the skull ${ }^{2}$ and spinal cord. ${ }^{1,3}$ Presumably, it is the compliance (or capacitance) ${ }^{2}$ that accommodates some of the increased volume due to transient cerebral edema or, more catastrophically, from intracerebral bleeds. The traditional explanation for brain injury in closed head trauma is due to exhaustion of the intracranial compliance.

An interesting additional mechanism of brain injury has recently been proposed. Head trauma results in pressure waves traversing the brain and reflecting inside the skull summing and cancelling as the wave paths cross. These pressure waves give rise to shearing forces on the delicate axons and dendrites causing widespread neuronal disruptions. "Slosh" destabilizes a tanker truck with a partially filled tank when it changes direction. For the truck, the solution is to fill the tank. By analogy, it has been suggested that "topping up" intracranial venous blood by applying gentle external compression on the internal jugular vein (IJV) with a cervical collar decreases compliance in the skull and could prevent slosh in the brain. Furthermore, Hatt et al. have shown that, in supine healthy volunteers, the blood distributed throughout the brain due to IJV compression increases the viscoelastic properties (i.e., its stiffness) of brain tissue in a nonlinear fashion. ${ }^{4}$ Although studies in rats ${ }^{5,6}$ were consistent with the mechanism of injury and its mitigation by jugular venous compression, it is not certain that jugular compression will result in the intracranial blood retention required to protect against slosh in upright humans.

Cerebral venous blood flows from the superior sagittal and straight sinuses via the transverse and sigmoid sinuses into the IJVs and subsequently drains into the superior vena cava via the brachiocephalic vein. ${ }^{7,8}$ In the supine position, the IJVs represent the main cerebral venous outflow. ${ }^{7}$ When upright, the alternate venous drainage pathway through the vertebral venous plexus predominates. This venous network courses along the spinal cord and ultimately drains into the inferior vena cava. ${ }^{7,8}$ Indeed, it has been claimed that, in the upright posture, flow is redirected from the IJV to the cervical venous plexus and often ceases entirely in the IJV. ${ }^{9}$ In this case, IJV compression would not cause a backup of blood and an increase in intracranial venous volume.

On the other hand, our experience as anesthesiologists suggests otherwise. ${ }^{10}$ The head-up positions were commonly used in neurosurgical procedures as they facilitated brain relaxation and minimized venous bleeding due to reduced venous pressure. It has been frequently observed that, in this setting, jugular venous compression or kinking of the vein by turning the head increases cerebral venous engorgement. ${ }^{11}$

The objective of this study was to examine IJV blood flow in healthy volunteers using two-dimensional (2D) echography and Doppler in the sitting position during a Valsalva maneuver and application of IJV external compression. Our hypothesis was that IJV blood flow continues while sitting and that circumferential supraclavicular IJV pressure and the Valsalva maneuver would result in progressive cephalad IJV filling.

\section{Methods}

Participants

This study was approved by the Institutional Research Ethics Board at the University Health Network, Toronto. The inclusion criteria were healthy adult volunteers $>18 \mathrm{yr}$ of age with a body mass index of $\leq 35 \mathrm{~kg} \cdot \mathrm{m}^{-2}$ Twelve 
subjects (four female) provided informed consent for the study.

The volunteers were kept comfortable in the sitting position. The cricoid cartilage (representing the C6 level) was used as a landmark. A horizontal straight line drawn across the volunteer's neck at the cricoid level and intersecting the IJV on both sides of the neck marked the initial scanning points.

The second scanning point was along the IJV at the highest accessible point on the neck.

Internal jugular vein cross-sectional area and blood velocity were measured using 2D ultrasound and Doppler (Philips CX50, Andover, MA, USA), respectively, with a 12-3 MHz transducer (Philips L12-3, Andover, MA, USA). The IJV cross-sectional area was obtained by manually using the ultrasound caliper to trace the circumference of the IJV. Velocities of IJV flow were measured using pulsed-wave Doppler and angle correction (Fig. 1). Extrinsic venous compression was controlled by measuring through a large bead of ultrasound gel to avoid, as much as possible, contacting the skin with the ultrasound transducer. The IJV measurements were obtained at the end of inspiration. The IJV flow was calculated using the following equation:

Flow $\left(\mathrm{mL} \cdot \mathrm{min}^{-1}\right)=$ Cross-sectional area $\left(\mathrm{cm}^{2}\right) \times$ Doppler velocity $\left(\mathrm{cm} \cdot \mathrm{sec}^{-1}\right) \times 60 \mathrm{sec} \cdot \mathrm{min}^{-1} \cdot 12$

Measurements of the participants' right and left IJVs were taken in accordance with the following conditions:

- normal breathing at rest

- during the Valsalva maneuver
- with standardized external compression of both IJVs

During the Valsalva maneuver, the volunteers were instructed to inspire deeply and expire forcefully through a closed glottis for $30 \mathrm{sec}$. Compression was achieved with a band incorporating two rectangular sponge pads $(2 \mathrm{~cm} \times 3$ $\mathrm{cm})$ designed to fit over the IJVs. A $100-\mathrm{mL}$ saline bag attached to a calibrated pressure transducer (TruWave; Edwards Lifesciences, Irvine, CA, USA) was placed at the back of the volunteer's neck, and the transducer was positioned at the level of the pad. The band was tightened by traction of the elastic strap leveraged over a buckle until the pressure read $15 \mathrm{mmHg}$. The strap was then fixed in place by engaging it with the Velcro burrs on the band (Fig. 2).

Data collection and statistical analysis

The data were entered and analyzed using Microsoft Excel (Microsoft Inc., Redmond, WA, USA). Continuous variables were summarized as mean (standard deviation [SD]) or median [interquartile range (IQR)]. Comparisons of the cross-sectional area, peak velocity, and flow measurements at rest, during Valsalva maneuver, and application of the cervical collar were made using the paired Student's $t$ test, the Wilcoxon test, or the MannWhitney $\mathrm{U}$ test as appropriate.

Results with $P$ value $<0.05$ were considered statistically significant.

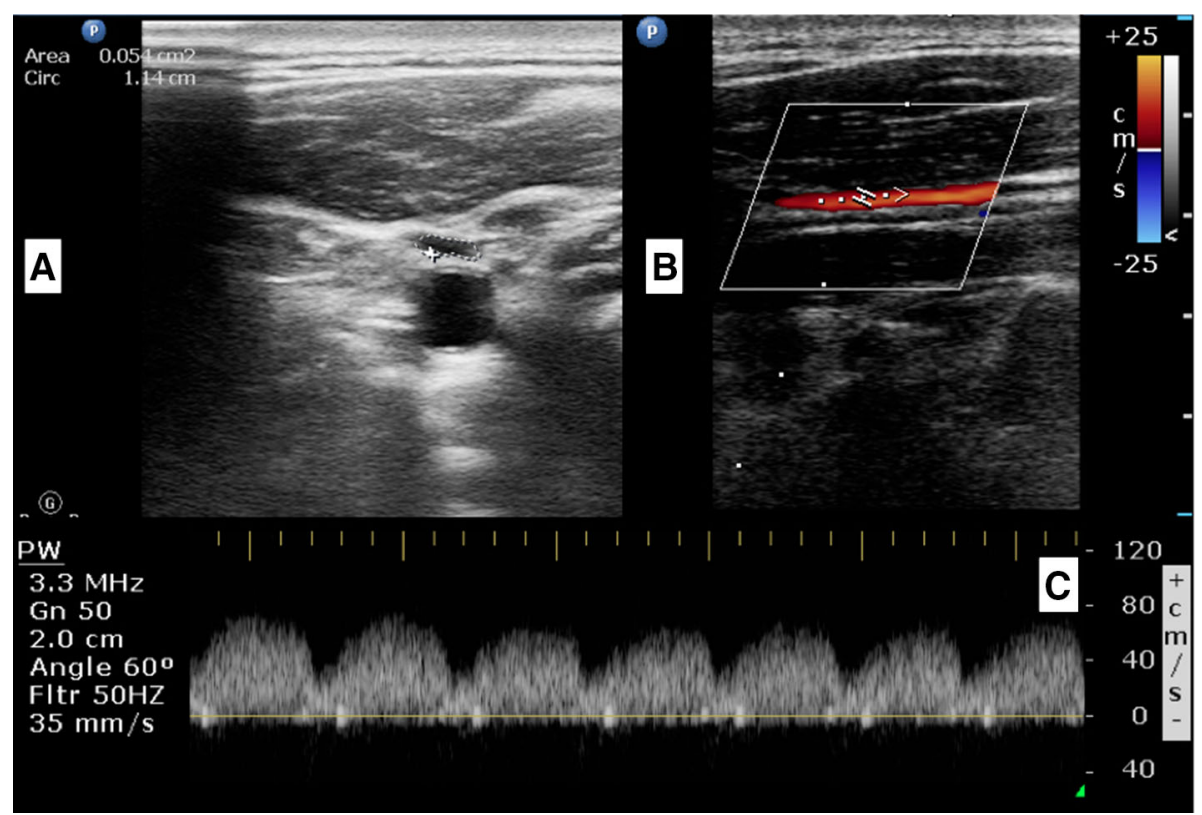

Fig.1 Assessment of internal jugular venous flow in a subject in the sitting position. A) Cross-sectional area at the cricoid level. B) Colour flow Doppler in the long-axis view and positioning of the pulsed-wave Doppler sample volume. C) Spectral Doppler trace 


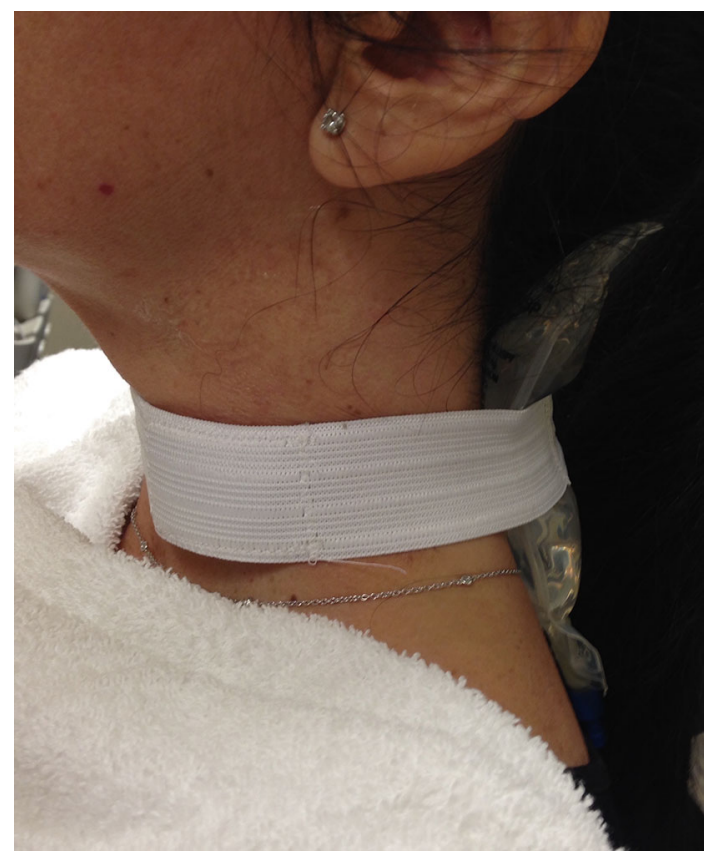

Fig.2 Compression band positioned and tension set at $15 \mathrm{mmHg}$ transduced pressure

\section{Results}

Two subjects (one male and one female) were eliminated for poor compliance to neck strap and inability to maintain prolonged Valsalva maneuver. The Table summarizes the comparisons of IJV cross-sectional areas, peak velocities, and flows in the sitting position at rest and with application of the cervical collar. At rest, flows and cross-sectional areas were measured in both ${ }^{2}$ the right and left IJVs. After application of the cervical collar, there was a significant increase in the median cross-sectional areas of both IJVs; however, there was no significant change in the median blood flow in the right IJV. Similarly, the difference in median blood flow in the left IJV at rest and with collar application was not substantive. The mean (SD) collar pressure was 15 (1.2) $\mathrm{mmHg}$.

During the Valsalva maneuver, there was an increase in the median cross-sectional area of both the right and left IJV.

\section{Discussion}

This study addresses some uncertainties about the effect of circumferential neck compression on cranial venous outflow in the upright posture. Whereas it was not clear to what extent, if at all, the IJVs continue to drain the intracranial venous return in upright humans, our study showed that IJV flow continued in both IJVs in all subjects.
This indicates that the maintenance of IJV flow is common rather than exceptional. Indeed, this novel study shows that moderately increasing IJV outflow resistance in the upright posture causes the blood to back up cephalad of the resistance - distending the IJVs. We ascertain that, having done so, the pre-occlusion IJV flow was restored, indicating the re-establishment of increased brain stiffness and a greater hydrostatic pressure gradient. ${ }^{4}$ Continued flow of at least part of the venous return from the brain via the IJV (as opposed to complete diversion to cervical plexus) is crucial to maintaining brain stiffness. ${ }^{4}$

The Valsalva maneuver also expanded the IJV. This is often attributed to extending an increase in central venous pressure up the IJV. ${ }^{13}$ Nevertheless, intrathoracic pressures would not be transmitted to the brain in the presence of competent IJV valves ${ }^{10,14-16}$; rather, it is evidence of continuous IJV flow and filling from above.

Based on previous literature, the effect of posture on cerebral venous drainage has been controversial. In the supine position, $74-95 \%$ of the cerebral venous blood drains through the IJVs. ${ }^{9,17,18}$ A change in posture from supine to sitting results in a redistribution of venous drainage from the IJVs to alternative extra-jugular venous pathways. ${ }^{9,17-19}$ As well, the increased drainage of blood reduces the superior venous sinus and CSF pressure, often below atmospheric pressure, and the internal jugular veins collapse, acting like Starling resistors. ${ }^{15,16}$ Valdueza et al. ${ }^{9}$ used Doppler ultrasound in the upright posture and reported a $50 \%$ reduction in venous flow and a marked $90 \%$ redistribution of flow away from the IJV. With a $15^{\circ}$ headup tilt, two of 23 subjects showed no flow in the IJV, and at a $90^{\circ}$ tilt, 9/23 subjects showed no flow. In contrast, Alperin et al. ${ }^{17}$ used much more accurate and reproducible magnetic resonance imaging (MRI) methods and found that only approximately $50 \%$ of IJV flow shifts away from the IJVs. Still, they found complete collapse of the IJV in the smallest (non-dominant) vein in 5/10 participants (and bilateral collapse in only 3/10). More recently, Ciuti et al. ${ }^{18}$ used more accurate and sensitive ultrasound sensors and, taking care to transduce through generously applied gel and to avoid any pressure on skin, they observed that the IJVs are not only "rarely occluded" but they conduct about a third of venous return. 9,17 Our results are consistent with this latter study. We detected IJV flow bilaterally in all ten subjects. The median IJV flow was considerable at $\sim 200$ $\mathrm{mL} \cdot \mathrm{min}^{-1}$ (compared with $70 \mathrm{~mL} \cdot \mathrm{min}^{-1}$ for Valdueza et al., ${ }^{9} 300 \mathrm{~mL} \cdot \mathrm{min}^{-1}$ for Alperin et al., ${ }^{17}$ and 100 $\mathrm{mL} \cdot \mathrm{min}^{-1}$ for Ciuti et al.). ${ }^{18}$

An important observation by Alperin et al. ${ }^{17}$ was the increase in intracranial compliance on assuming the erect posture. This increase in compliance and reduction in intracranial pressure is based on a reduction in blood volume of only a few milliliters, yet it is associated with a 
Table Comparisons of bilateral internal jugular vein cross-sectional area, peak velocity, and flow in the sitting position at rest and with application of the cervical collar $(n=10)$

\begin{tabular}{|c|c|c|c|c|c|c|}
\hline & \multicolumn{3}{|c|}{ Right Internal Jugular Vein } & \multicolumn{3}{|c|}{ Left Internal Jugular Vein } \\
\hline & Rest & Collar* & $P$ value & Rest & Collar* & $P$ value \\
\hline Cross-sectional area at $\mathrm{C} 6\left(\mathrm{~cm}^{2}\right)$ & $0.04[0.03-0.08]$ & $0.4[0.2-0.6]$ & 0.003 & $0.07[0.05-0.13]$ & $0.35[0.17-0.44]$ & 0.04 \\
\hline High cross-sectional area $\left(\mathrm{cm}^{2}\right)$ & $0.04[0.02-0.06]$ & $0.21[0.17-0.30]$ & $<0.001$ & $0.05[0.03-0.09]$ & $0.13[0.11-0.15]$ & 0.002 \\
\hline Peak velocity $\left(\mathrm{cm} \cdot \mathrm{sec}^{-1}\right)$ & $70[9-116]$ & $17[10-22]$ & 0.16 & 30 [22-47] & $12[5-16]$ & 0.03 \\
\hline Flow at $\mathrm{C} 6\left(\mathrm{~mL} \cdot \mathrm{min}^{-1}\right)$ & $193[50-491]$ & 349 [262-488] & 0.27 & $113[93-323]$ & 183 [78-389] & 0.88 \\
\hline Flow at high cross-sectional area $\left(\mathrm{mL} \cdot \mathrm{min}^{-1}\right)$ & $121[23-328]$ & $236[114-503]$ & 0.27 & $105[38-170]$ & 889 [36-206] & 0.88 \\
\hline
\end{tabular}

Data are presented as median [interquartile range]. *Mean (standard deviation) collar pressure is $15(1.2) \mathrm{mmHg}$

marked reduction in intracranial pressure (2.4 times) as well as in venous and CSF pulsatility. In normal day-to-day life and under all normal activity, this increase in compliance does not cause any health concerns.

Recently, new considerations of intracranial compliance have been added to those of surgical positioning. Head trauma and explosive blast waves result in displacement of the brain relative to the skull ("rattle") and in conduction of energy in the form of waves through the brain parenchyma, i.e., "slosh". 5 In slosh, pressure waves traverse the brain, $\mathrm{CSF}$, and blood. This generates shearing forces and results in widespread diffuse damage to neurovascular structures. Smith et $a .^{5}$ showed that applying a collar to lessen intracranial venous outflow reduces intracranial compliance and thereby reduces the damage from rattle (i.e., the coup and contrecoup injuries) and slosh in a rat traumatic brain injury model. Nevertheless, if the IJVs are indeed collapsed and have no flow in an upright posture, it would be pointless to obstruct the IJVs to reduce cerebral compliance. Toung et al. studied the effects of IJV pressure on cerebral venous pressure in dogs in the vertical position. ${ }^{15}$ They found that $40 \mathrm{mmHg}$ of circumferential pressure on the IJVs established a continuous fluid column to the cerebral veins, which increased and sustained venous pressure over atmospheric pressure for the duration of the inflation (20 min). All conditions reverted to baseline when the tourniquet was released. Our study provides some optimism with respect to use of external IJV compression in humans. We showed IJV flow in all of our subjects, as did Ciuti et al. ${ }^{18}$ Compared with the use of a circumferential tourniquet, our obstructing band exerted only $15 \mathrm{mmHg}$ of pressure focused over each IJV. It nevertheless increased the cross-sectional areas of the IJV cephalad to the obstruction. This implies filling from above, as the pressure at the root of the neck and the valves in the lower part of the IJVs prevented filling from below. This is consistent with our finding of persistent flow in the IJV at rest. With compression, the IJVs must fill before the hydrostatic pressure is reflected into the skull. The volume of the IJV above the compression is about $6 \mathrm{~mL}^{13}$
Assuming the flow of $200 \mathrm{~mL} \cdot \mathrm{min}^{-1}$ found in this study, it would take about two seconds to fill and encroach on intracranial compliance.

One of the limitations of our study is the small sample size. The inconsistencies in the observations of IJV flow under sitting/standing conditions may be related to differences in opening pressures of the venous systems in the neck. When venous distending pressure is less than the opening pressure (e.g., in the standing position), the IJVs collapse. Hatt et $a l^{4}{ }^{4}$ showed increased stiffness with jugular venous resistance, but the subjects were supine. With respect to protection from traumatic brain injury, we do not have access to an upright MRI unit and were therefore unable to measure intracranial compliance. Nevertheless, as mentioned above, studies in $\operatorname{dogs}{ }^{15}$ and in humans with open crania $^{16}$ confirm brain hyperemia with IJV compression in upright humans. We can therefore only assume that this would reduce compliance, increase stiffness, and minimize slosh and the accompanying brain injury. $^{20}$

We made only one measurement for all required parameters, and this may have reduced the reliability of the data. Nevertheless, it would not have changed the general conclusions regarding the main observations reported in the study-i.e., upright posture and its effect on the patency of the IJV, development of a blood column and its effect on increasing the resistance of outflow, and the persistence of centripetal flow. We used a custom-made collar and arbitrarily chose $15 \mathrm{mmHg}$ as the representative pressure that compressed most IJVs and was accepted as comfortable by all our subjects. In our view, the scientific principles deduced from a pressure of $15 \mathrm{mmHg}$ will apply to a lesser or greater degree with IJV pressures of 10-20 $\mathrm{mmHg}$.

\section{Conclusions}

Notwithstanding substantial venous return from a cervical plexus of veins, in the upright posture, the IJVs are patent 
in most, if not all, healthy people and have persistent centripetal flow. In the upright posture, outflow resistance due to external compression or increased central venous pressure may increase intracranial venous volume, increase brain stiffness, and reduce intracranial compliance.

Conflicts of interest None declared.

Editorial responsibility This submission was handled by Dr. Philip M. Jones, Associate Editor, Canadian Journal of Anesthesia.

Author contributions Tze Yeng Yeoh performed data analysis and wrote the first draft of the manuscript. Massimiliano Meineri, Lashmi Venkatraghavan, and Joseph A. Fisher conceived the study, contributed to data collection and analysis, and edited the manuscript.

\section{References}

1. Bhadelia RA, Bogdan AR, Kaplan RF, Wolpert SM. Cerebrospinal fluid pulsation amplitude and its quantitative relationship to cerebral blood flow pulsations: a phase-contrast MR flow imaging study. Neuroradiology 1997; 39: 258-64.

2. Rekate HL, Nadkarni TD, Wallace D. The importance of the cortical subarachnoid space in understanding hydrocephalus. J Neurosurg Pediatr 2008; 2: 1-11.

3. Greitz D, Wirestam $R$, Franck A, Nordell B, Thomsen $C$, Stahlberg F. Pulsatile brain movement and associated hydrodynamics studied by magnetic resonance phase imaging. The Monro-Kellie doctrine revisited. Neuroradiology 1992; 34: 370-80.

4. Hatt A, Cheng $S$, Tan $K$, Sinkus R, Bilston LE. MR elastography can be used to measure brain stiffness changes as a result of altered cranial venous drainage during jugular compression. AJNR Am J Neuroradiol 2015; 36: 1971-7.

5. Smith DW, Bailes JE, Fisher JA, Robles J, Turner RC, Mills JD. Internal jugular vein compression mitigates traumatic axonal injury in a rat model by reducing the intracranial slosh effect. Neurosurgery 2012; 70: 740-6.

6. Turner RC, Naser ZJ, Bailes JE, Smith DW, Fisher JA, Rosen CL. Effect of slosh mitigation on histologic markers of traumatic brain injury: laboratory investigation. J Neurosurg 2012; 117 : 1110-8.

7. Schreiber SJ, Lurtzing F, Gotze $R$, Doepp $F$, Klingebiel $R$, Valdueza JM. Extrajugular pathways of human cerebral venous blood drainage assessed by duplex ultrasound. J Appl Physiol 1985; 2003(94): 1802-5.

8. Doepp F, Schreiber SJ, von Munster T, Rademacher J, Klingebiel $R$, Valdueza JM. How does the blood leave the brain? A systematic ultrasound analysis of cerebral venous drainage patterns. Neuroradiology 2004; 46: 565-70.

9. Valdueza JM, von Munster T, Hoffman O, Schreiber S, Einhaupl $K M$. Postural dependency of the cerebral venous outflow. Lancet 2000; 355: 200-1.

10. Fisher J, Vaghaiwalla F, Tsitlik $J$, et al. Determinants and clinical significance of jugular venous valve competence. Circulation 1982; 65: 188-96.

11. Losasso TJ, Muzzi DA, Cucchiara RF. Jugular venous compression helps to identify the source of venous air embolism during craniectomy in patients in the sitting position. Anesthesiology 1992; 76: 156-7.

12. Vailati D, Lamperti $M$, Subert $M$, Sommariva A. An ultrasound study of cerebral venous drainage after internal jugular vein catheterization. Crit Care Res Pract 2012; 2012: 685481.

13. Cirovic $S$, Walsh C, Fraser WD, Gulino A. The effect of posture and positive pressure breathing on the hemodynamics of the internal jugular vein. Aviat Space Environ Med 2003; 74: 125-31.

14. Silva MA, Deen KI, Fernando DJ, Sheriffdeen AH. The internal jugular vein valve may have a significant role in the prevention of venous reflux: evidence from live and cadaveric human subjects. Clin Physiol Funct Imaging 2002; 22: 202-5.

15. Toung T, Ngeow YK, Long DL, Rogers MC. Traystman RJ Comparison of the effects of positive end-expiratory pressure and jugular venous compression on canine cerebral venous pressure. Anesthesiology 1984; 61: 169-72.

16. Grady PA, Blaumanis OR. Cerebral venous blood gas tensions in elevated intracranial pressure. Stroke 1986; 17: 946-52.

17. Alperin N, Lee SH, Sivaramakrishnan A, Hushek SG. Quantifying the effect of posture on intracranial physiology in humans by MRI flow studies. J Magn Reson Imaging 2005; 22: 591-6.

18. Ciuti G, Righi D, Forzoni L, Fabbri A, Pignone AM. Differences between internal jugular vein and vertebral vein flow examined in real time with the use of multigate ultrasound color Doppler. AJNR Am J Neuroradiol 2013; 34: 2000-4.

19. Gisolf J, van Lieshout JJ, van Heusden K, Pott F, Stok WJ, Karemaker JM. Human cerebral venous outflow pathway depends on posture and central venous pressure. J Physiol 2004; 560: 317-27.

20. Myer GD, Yuan W, Barber Foss KD, et al. The effects of external jugular compression applied during head impact exposure on longitudinal changes in brain neuroanatomical and neurophysiological biomarkers: a preliminary investigation. Front Neurol 2016; 7: 74. 